\title{
Crisis del Estado de derecho en Colombia: un análisis desde la perspectiva de la legislación penal*
}

\author{
Hugo Fernando Saidiza Peñuela* \\ Jorge Enrique Carvajal Martínez
}

Recibido: 5 de enero de 2016 • Revisado: 20 enero de 2016

Aprobado: 22 de febrero de 2016

\section{Resumen}

El presente artículo pretende advertir la crisis a la que se ha visto abocado el modelo de Estado de derecho, así como el deterioro del sistema de garantías que le es inherente, como consecuencia de la incursión en el escenario global del discurso de la seguridad, el cual se ha establecido como estandarte de la denominada lucha contra el terrorismo. En el contexto del paradigma securitario, se establece un derecho penal de cuño autoritario que soslaya los postulados liberales y democráticos que deberían informar su práctica y servir de límite al poder punitivo, de este modo, se pretende ofrecer un marco contextual y conceptual que nos permita determinar la función que cumple el derecho penal en este panorama específico.

Palabras clave: Estado de Derecho, Derecho Penal, evolución estatal.

" El documento es producto del proyecto de investigación: «Nuevas» lógicas autoritarias y crisis del Estado de Derecho en Colombia. Un Análisis de la legislación penal de emergencia inscrita en el manejo jurídico de la protesta social", con el cual el Doctor Fernando Saidiza obtuvo el título de Abogado en la Universidad Santo Tomas (sede Bogotá).

* Abogado egresado de la Universidad Santo Tomás. Candidato a Magister en Sociología en la Universidad Nacional de Colombia. Correo electrónico: fernandoddhh@gmail.com.

**o PhD en Sociología Jurídica e Instituciones Políticas - Universidad Externado de Colombia. $\mathrm{El}$ autor ha sido docente e investigador de varias Universidades del País, entre ellas, las Universidades Nacional, Libre y Santo Tomas. Correo electrónico: jecarvajalma@gmail.com. 


\title{
Crisis of the Rule of Law in Colombia: An analysis from THE PERSPECTIVE OF CRIMINAL LEGISLATION
}

\begin{abstract}
This article is intended to alert the crisis that has been doomed model rule of law as well as the deterioration of the guarantee system that is inherent, as a result of the raid on the global stage speech security, which it has been established as the standard of the so-called fight against terrorism. In the context of this security paradigm, a criminal law authoritarian stamp that ignores liberal and democratic principles that should inform their practice and serve as a limit to punitive power, thus established it is intended to provide a context and conceptual framework that allows us determine the role of the criminal law in this specific scenario.
\end{abstract}

Keywords: Rule of law; Criminal law; state development.

\section{Crise do Estado de direito na Colômbia: uma análise a PARTIR DA PERSPECTIVA DA LEGISLAÇÃO PENAL}

\section{Resumo}

O presente artigo tem o objetivo de alertar a crise à que se tem votado o modelo de Estado de direito, e a deterioração do sistema de garantia que lhe é inerente, como resultado da incursão no cenário global do discurso da segurança, o qual foi estabelecido como o estandarte do assim chamado combate ao terrorismo. No contexto deste paradigma de segurança, estabelece-se um direito penal de cunho autoritário que contorna os princípios liberais e democráticos que deveriam informar a sua prática e servir como um limite para o poder punitivo, assim visa-se oferecer um quadro contextual e conceitual que nos permite determinar o papel que tem o direito penal neste cenário específico.

Palavras-chave: Estado de Direito, Direito Penal, evolução do estado.

\section{Introducción}

Siendo el Estado el responsable del disfrute de los derechos de los ciudadanos, al tiempo que el principal actor en la violación de los derechos humanos de las personas que continuamente protestan por el cumplimiento y exigencia de sus 
derechos, es menester reclamar desde la academia y desde la organización política y social, una contención de este poder ilimitado del Estado, que pasa sin lugar a dudas, por la exigencia y plena observancia de los lineamientos de la Constitución de 1991 y en materia penal, de la dogmática y principios liberales que informan la práctica penal, para que no se convierta este en una herramienta aniquiladora de sectores sociales antagónicos al Estado.

\section{Estado de derecho: una sucinta descripción sobre su génesis, desarrollo y características. El camino hacia el paradigma securitario}

\subsection{Los orígenes del Estado y la cuestión de la seguridad pública}

Partimos de la idea, según la cual, se debe entender el concepto de Estado como construcción histórica. Concebir el Estado de esta forma permitirá identificar los actores y contextos específicos que contribuyeron en la evolución de los diferentes modelos del Estado, al tiempo que, nos ayudará a trazar una breve línea del tiempo, que sirva en la identificación de los procesos de transición hacia la creación del moderno Estado de derecho.

Desde luego, no es la intención advertir con rigurosidad todos los procesos de la transición mencionada, labor extensa que desbordaría los objetivos del presente artículo, sino más bien identificar algunos elementos esenciales de la naturaleza del Estado, que a la postre permitirán construir el marco de análisis en el que se moverá la presente investigación.

Bajo ese entendido, tomaremos como punto de partida la época histórica en la que se puede empezar hablar de Estado. Así nos indica Perry Anderson que es "en el transcurso del siglo XVI donde aparece en Occidente la concepción de Estado absolutista" (1979, p. 9). Según el autor, la incursión de este modelo de Estado obedeció a que "las monarquías centralizadas de Francia, Inglaterra y España representaron una ruptura decisiva con la soberanía piramidal y fragmentada de las formaciones sociales medievales, con sus sistemas de feudos y estamentos" (p. 9).

Dicha ruptura entre la sociedad medieval y las monarquías absolutas favoreció el paulatino desarrollo de "ejércitos y una burocracia permanentes, un sistema nacional de impuestos, un derecho codificado y los comienzos de un mercado unificado" 
(Anderson, 1979, p. 11). Las mencionadas características permiten identificar la "aparición de un concepto desarrollado de Estado, a través de la centralización del poder y de un territorio unificado y claramente delimitado" (Melossi, 1992, p. 32).

En virtud de lo anterior, podemos advertir que los procesos de transformación de las sociedades feudales hacia las monarquías absolutas generaron cambios progresivos en la forma de concebir el poder. En efecto, la paulatina concentración y centralización del poder coercitivo en manos del monarca, se inscribirá como una de las características fundamentales del absolutismo. Así lo explica Anderson cuando expone que el

\section{[...] desplazamiento de la coerción política en un sentido ascendente hacia una cima centralizada y militarizada, se puede identificar con: el Estado absolutista. [...] E1 resultado de este proceso fue un aparato reforzado de poder real, cuya función politica permanente era la represión de las masas campesinas y plebeyas en la base de la jerarquía social. Esta nueva maquinaria de Estado, sin embargo, estaba investida por su propia naturaleza de una fuerza coactiva capaz de destruir o disciplinar a individuos y grupos enteros. (1979, p. 14, cursivas fuera del original)}

Junto a los procesos de disciplinamiento y represión identificados, el Estado absolutista adquiere además, como rasgo característico de su naturaleza, la preocupación por la seguridad pública externa, la cual se ve fuertemente amenazada por el contexto generalizado de violencia que marcó a Europa en los siglos XVI y XVII.

Sobre este contexto, se refiere Anderson cuando nos cuenta que según "cálculos en todo el siglo XVI solo hubo veinticinco años sin operaciones militares de largo alcance en Europa; y que en el siglo XVII solo transcurrieron siete años sin grandes guerras entre estados" (1979, p. 28). De allí que Maquiavelo al estudiar la Europa del siglo XVI hubiese afirmado que "un príncipe no debe tener otro pensamiento, ni cultivar otro arte más que la guerra, el orden y la disciplina de los ejércitos, porque éste es el único arte que se espera ver ejercido por el que manda" (Maquiavelo, 1978, p. 62).

Este constante desasosiego por la seguridad pública, tanto a nivel interno como externo, se torna en cuestión fundamental para la constitución del Estado absolutista, al tiempo que funge como criterio de necesidad y legitimación de este particular modelo de Estado. Así la cuestión de la seguridad, se toma como "fundamento del «pacto originario» que realizan los individuos para salir del pobre estado de naturaleza en donde no hay derecho alguno" (Zaffaroni, 2011, p. 17). 
A partir de la constitución del Estado absoluto, el soberano goza de privilegios discrecionales para determinar qué opiniones, juicios y parámetros son los apropiados para garantizar y mantener la seguridad dentro del Estado. Así, aquellas visiones o doctrinas que se opongan a las del soberano serán susceptibles de ser perseguidas y censuradas, contemplándose un primigenio fundamento a partir del cual se desconocen, por parte del soberano, los límites y las garantías que formalmente tienen los súbditos a la hora de enfrentar el juzgamiento por sus conductas punibles, abriendo paso, de esta manera, a un absolutismo en materia penal.

Ejemplo de lo anterior son algunas referencias de la obra de Thomas Hobbes, donde se puede establecer con meridiana claridad la aplicación de un derecho de guerra a quienes son señalados por el poder como enemigos del «pacto originario»

\section{[...] los súbditos que deliberadamente niegan la autoridad del Estado establecido [...] renuncian a la subordinación, lo cual constituye una recaída en la condición de guerra, comúnmente llamada rebelión; y quienes así ofenden no sufren como súbditos, sino como enemigos, ya que la rebelión no es sino guerra renovada. (1994, p. 260, cursivas fuera del original)}

En la idea hobbesiana de fundación del Estado mediante la figura del «pacto originario» queda eliminada cualquier posibilidad de un derecho de rebelión para los súbditos, de tal manera que quienes se atrevan a desafiar el poder absoluto del soberano, "no serán juzgados mediante los procedimientos establecidos por las leyes civiles, sino que se les aplicará el derecho de la guerra, siendo tratados como enemigos del Estado" (Ramírez, 2010, p. 88, cursivas fuera del original).

Así las cosas, Hobbes establece un proceso diferenciado para juzgar a aquellos que desconozcan la autoridad del soberano, de tal manera que el castigo a los considerados «rebeldes» no se entenderá como pena, sino más bien -en opinión de Hobbes- como un legítimo acto de guerra, cumpliéndose con la voluntad de venganza del soberano. Advierte Hobbes que

[...] el daño infringido a quien se considera enemigo no queda comprendido bajo la denominación de pena, [...] todos los daños que puedan inferírsele deben ser considerados como actos de hostilidad. Ahora bien, en casos de hostilidad declarada toda la aflicción de un mal es legal. De lo cual se sigue que si un súbdito, de hecho o de palabra, con conocimiento y deliberadamente, niega la autoridad del 
representante del Estado, puede legalmente hacérsele sufrir cualquier daño que el representante quiera, ya que al rechazar la condición de súbdito rechaza la pena que ha sido establecida por la ley, y, por consiguiente, padece ese daño como enemigo del Estado, es decir, según la voluntad del representante. En cuanto a los castigos establecidos por la ley, son para los súbditos, no para los enemigos, y han de considerarse como tales quienes, habiendo sido súbditos por sus propios actos, al rebelarse deliberadamente niegan el poder soberano. (1994, pp. 256-257)

Asimismo en su obra El Ciudadano, Hobbes expone claramente que

[...] se castiga a los rebeldes, traidores y demás convictos de lesa majestad no según el derecho civil sino según el natural; esto es, no como a malos ciudadanos sino como a enemigos del Estado; y no por derecho de gobierno o de dominio sino por derecho de guerra. (1993, p. 133)

En la lógica contractualista del filósofo inglés, el delito más grave es aquel que desconoce el pacto fundacional del Estado, por lo tanto el «rebelde» "con su acto ha traicionado, no solo al soberano, sino también a los demás asociados, por lo cual será tratado no como un súbdito -un igual-, sino como un enemigo -el otro- que deberá ser eliminado" (Ramírez, 2010, p. 93).

\subsection{Del Estado absolutista al Estado liberal burgués. El «liberalismo» de Locke como reacción al Estado-leviatán hobbesiano}

En términos políticos y sociales, la concentración del poder en manos del soberano y el ejercicio arbitrario del mismo, como consecuencia de la imposibilidad de establecer límites y controles al ejercicio de la autoridad, produjo una amplia reacción en contra del Ancien régime, por parte de sectores de la burguesía principalmente. Esta reacción se vio favorecida, entre otros factores, por las nuevas concepciones científicas, filosóficas, económicas y políticas que partieron con el Renacimiento, asimismo, hechos de honda significancia como las revoluciones liberales de Inglaterra de 1689, de la Constitución de Filadelfia de 1787 y posteriormente la Revolución Francesa de 1789, contribuyeron al surgimiento y difusión del ideario liberal de finales del siglo XVII y a lo largo del siglo XVIII que condujo a la paulatina transformación del Estado absoluto por el Estado liberal burgués. 
Como fundamento ideológico de las transformaciones liberales de la época, podemos rescatar la teoría política de John Locke expuesta en su obra El ensayo sobre el gobierno civil, la cual ha sido "tradicionalmente identificada como polaridad política con el pensamiento hobbesiano" (Zaffaroni, 2011a, p. 134). En la visión de Locke, el pacto fundador del Estado es en realidad un pacto de asociación mediante el cual los hombres, a través de su consentimiento, renuncian a la posibilidad de hacer justicia por sí mismos y se someten en adelante al principio de la mayoría.

Para este pensador (Locke) en los momentos pre-estatales hay una sociedad civil (no es un Estado de guerra) y encontramos una serie de derechos que él denomina "naturales", entre los que subraya el de la vida y la propiedad privada. Postula que los hombres viven en este estado de naturaleza en una situación de paz y sometidos a leyes naturales que surgen de la razón. Los hombres salen a través del pacto social del estado de naturaleza porque no existe allí justicia imparcial que asegure los derechos naturales y por la necesidad de proteger la vida y la propiedad contra los atentados de transgresores. El fundamento de este pacto es salvaguardar estos derechos naturales que no están garantizados en un estado de naturaleza. (Zaffaroni, 2011, p. 20)

Si este fin no se cumple -el de salvaguardar los derechos naturales- o se presenta un abuso de poder por parte del soberano, los ciudadanos quedan en libertad de derrocarlo y establecer otro gobierno, consagrándose en el pensamiento lockeano el derecho a la rebelión -en contraposición a Hobbes donde no hay lugar a tal derecho-. Escribe Locke:

[...] cuando al pueblo se le hace sufrir y se encuentra expuesto a los abusos del poder arbitrario, la rebelión tendrá lugar, por mucho que se les diga que sus gobernantes son hijos de Júpiter, sagrados o divinos, descendidos de los cielos o autorizados por ellos, o cualquier otra cosa. (Locke, 1994, p. 215)

El derecho de resistencia a la opresión, resulta ser uno de los puntos de divergencia más notorios entre el pensamiento político de Locke y el de Hobbes, así para el primero

[...] quien realiza un acto de resistencia legitimo reclamando el respeto de derechos anteriores al contrato estatal, es un ciudadano que ejerce su derecho; para Hobbes, como defensor del estado absoluto, es un enemigo al que es menester contener con fuerza ilimitada, sin respetar siquiera los márgenes de la pena, porque ha dejado de ser un súbdito. Quien 
para Locke ejerce el derecho de resistencia a la opresión es para Hobbes un enemigo peor que un criminal. Para Locke el soberano que abusa del poder pierde su condición de tal y pasa a ser una persona más; para Hobbes es el súbdito que resiste el abuso de poder del soberano quien pierde su condición y pasa a ser un enemigo. (Zaffaroni, 2011a, p. 134, cursivas del original)

De esta manera, pretendemos advertir que la cuestión del enemigo pasa por una contraposición entre los principios del Estado absoluto y del Estado liberal, esto es entre la visión de Hobbes y Locke, "cuya clave se halla en el derecho a resistir la opresión, que los partidarios del estado absoluto no solo niegan, sino que asignan el carácter de enemigo a quien pretende ejercerlo" (Zaffaroni, 2011a, p. 138).

Así las cosas, se puede colegir del "contractualismo de Locke algunos de los más importantes principios del liberalismo clásico: derechos naturales inviolables, limitación al poder, separación de poderes como fuente del constitucionalismo, entre otros" (Ramírez, 2010, p. 20).

Partiendo del principio de la desconfianza hacia el poder, Locke establece una serie de límites al gobierno. En primer lugar, se debe mencionar la separación de poderes establecida en el capítulo 12 del Segundo tratado. La clara diferenciación y separación entre los poderes ejecutivo, legislativo y federativo constituye una de las bases fundamentales del constitucionalismo moderno, en oposición a la concentración del poder del pensamiento hobbesiano. (Ramírez, 2010, p. 20)

Los elementos que el liberalismo político fija al Estado, sin duda alguna, representan un importante avance en la construcción moderna de este concepto, toda vez que existe en esta concepción una garantía de protección a los derechos naturales y la posibilidad de limitar el poder político. Sin embargo, desde un punto de vista estricto, como el que expone Helio Gallardo haciendo eco de las interpretaciones de C. B. Macpherson en su trabajo sobre la democracia liberal, "los criterios de este autor inglés lo posicionan filosóficamente dentro de la tradición liberal nodemocrática" (citado en Gallardo, 2005, p. 193).

En concordancia con esta visión, se nos muestra la opinión de Darío Melossi cuando indica que Locke 
[...] afirmaba que los derechos políticos quedaban restringidos a los estratos poseedores de propiedades. [...] El nuevo orden político que diseñaba la construcción lockeana se basaba en aquellos individuos que eran hombres, propietarios, ciudadanos del estado y cabezas de familia. Los grandes segmentos de la población quedaban excluidos de la base social del nuevo orden. (1992, p. 38)

Esta visión particular del «liberalismo» presente en Locke, que lo separa de la concepción absoluta del Estado-leviatán hobbesiano, lo aparta también de la idea del «Estado de derecho», y lo hace coincidir más bien, con el concepto de «Estado gendarme» que se caracteriza por intervenir lo menos posible en la vida de las personas y reducir al mínimo su injerencia en los asuntos de la economía, limitándose fundamentalmente al mantenimiento del orden en la sociedad.

En este punto resulta necesario aclarar la dualidad contradictoria que se nos muestra encerrada en el término «liberalismo», toda vez que se pueden distinguir dos conceptos totalmente diferentes que yacen confundidos en este término; por un lado, a) el liberalismo entendido como sinónimo del Estado de derecho; y b) el liberalismo como una particular concepción política que reduce al mínimo la ingerencia (sic) del Estado en todos los órdenes de la vida social, particularmente en el económico (el "Estado gendarme") (Zaffaroni, 1996).

En la postura de Locke, el liberalismo que se nos muestra como sustento doctrinal de la garantía y protección de los derechos individuales es en realidad una protección restringida que se reserva únicamente para la clase poseedora de propiedades, lo cual permite establecer su consolidación como modelo de democracia restringida. En este sentido, el "Estado gendarme" debe dedicarse fundamentalmente a garantizar el control y el orden en la sociedad que permita perpetuar el estado de cosas del nuevo orden político y social. De tal manera que, cuando se pretenda transformar o alterar dicho orden, con las protestas o demandas sociales por ejemplo, el Estado deberá asumir un papel coercitivo, traduciéndose en la práctica en un agente represor de la población relegada del nuevo orden social.

Es por lo anterior, que resulta imperativo no solo aclarar la contradicción presente en el término liberalismo, sino también deslindar las dos concepciones de Estado que se desarrollan como expresión concreta de esta corriente filosófica, así nos lo sugiere Zaffaroni cuando indica que 
El vocablo «liberalismo» y sus derivados, privado de aclaración, es indeseable, porque encierra una dualidad contradictoria: abarca al Estado de derecho y a una de sus negaciones.

[...] «Estado de derecho» $\mathrm{y}$ «Estado gendarme» son dos concepciones del Estado que no debieran ser confundidas. El «Estado de derecho» solo puede ser un "Estado social de derecho", que debe realizar el derecho íntegramente, como garantía, pero no como garantía de un ámbito abstracto de libertad política, sino como garantía de que el hombre dispondrá de lo que le sea necesario -material y espiritualmente, lo que presupone la libertad política- para su realización en coexistencia, en sociedad. En este sentido, el "Estado gendarme" llega a ser solo una de las tantas formas de negar el Estado de derecho, convirtiéndose a la larga en una frustración patológica del Estado de derecho. (Zaffaroni, 1998, p. 366)

En consecuencia con lo anterior, la idea de «liberalismo» que predominará en el presente trabajo, es la que se encuentra vinculada con la noción de Estado de derecho y el sistema de garantías que le es inherente, desligándose de la concepción liberal-burguesa del Estado gendarme descrita anteriormente. En ese orden de ideas, identificaremos a continuación las características principales que dan sustento al Estado de derecho, entendido como Estado social y democrático de derecho, así como la crisis que este modelo atraviesa en la actualidad, la cual ha re-valorado la incursión de las tesis securitarias y la idea de Estados represivos encargados del mantenimiento del orden.

\subsection{Crisis del «Estado social» y fortalecimiento del Estado securitario}

Teniendo en cuenta que el Estado de derecho funda sus lineamientos sobre la base del pensamiento liberal, se puede asegurar, a manera de corolario de lo dicho hasta aquí, sobre el concepto de Estado de derecho que su desarrollo está inscrito en

[...] la tradición del pensamiento liberal, como un sistema de límites y prohibiciones negativos, correlativos a los derechos de libertad, oponibles únicamente al poder político. El Estado, según este modelo que bien podríamos llamar Estado liberal de derecho, se legitima por tanto esencialmente como «Estado mínimo», 
garante de las libertades y de las autonomías individuales a través de prohibiciones de lesión o de interferencia, es decir, de deberes de no hacer, en la esfera privada de los ciudadanos. (Ferrajoli, 2008, p. 293, cursivas del original)

El Estado liberal de derecho, se caracterizará entonces por fundar su legitimidad en la ley (principio de legalidad), en la separación de poderes (sistema de pesos y contra pesos), y en la garantía y protección de los derechos individuales, todo lo cual servirá como límite al poder absolutista. En palabras de Mir Puig

Este modelo de Estado aporta [...] la exigencia de que el ejercicio de los poderes públicos respete determinadas garantías formales, ciertos límites que aseguren la salvaguardia de las esferas de libertad formalmente reconocidas a los ciudadanos. El Estado liberal responde a la preocupación de defender a la sociedad del Estado, lo que pretende conseguir mediante la técnica formal de la división de poderes y el principio de legalidad. (1994, p. 31, cursivas del original)

Hasta aquí nos encontramos con una primera acepción del Estado de derecho, aquella en la que todos los órganos e instituciones del Estado están sometidos a derecho. Sin embargo, es menester advertir una segunda caracterización más fuerte del Estado de derecho, según la cual

[...] el Estado de derecho supone ya una vinculación directa con el Estado democrático. No basta el cumplimiento de los aspectos formales mencionados, sino que además exige el respeto de normas sustantivas que garanticen los derechos fundamentales del ciudadano ante el Estado. [...] El Estado de derecho en su acepción plena es inseparable del Estado democrático, así como éste no puede existir sin el cabal funcionamiento del Estado de derecho, formando una nueva unidad indisoluble, el «Estado democrático de derecho». (Sotelo, 2010, p. 116)

Esta indisoluble relación plasmada en el modelo «Estado democrático de derecho» supone a su vez el reconocimiento de las luchas sociales de la primera década del siglo XX que transformaron la concepción del Estado hacia el Estado bienestar o social. De esta manera, "los derechos civiles y políticos consagrados en el siglo XIX se complementarían con la idea de derechos sociales que implicaban 
una mayor intervención estatal por medio de la política económica y social" (Carvajal, 2008, pp. 52-53).

Esta segunda significación del Estado que podríamos relacionar con el Estado social y democrático de derecho supone -como advierte Luigi Ferrajoli-, un "«modelo garantista» ${ }^{1}$ como principal rasgo funcional de esta formación moderna del estado" (1997, p. 855). Explica el autor italiano que:

Estos diez principios, ordenados y conectados sistemáticamente, definen [...] el modelo garantista de derecho o de responsabilidad penal, esto es, las reglas del juego fundamentales del derecho penal. Fueron elaborados sobre todo por el pensamiento iusnaturalista de los siglos XVII y XVIII, que los concibió como principios políticos, morales o naturales de limitación del poder penal «absoluto». Y han sido ulteriormente incorporados, más o menos íntegra y rigurosamente, a las constituciones y codificaciones de los ordenamientos desarrollados, convirtiéndose así en principios jurídicos del moderno estado de derecho. (1997, p. 93, cursivas del original)

En la actualidad, advierte Enrique Bacigalupo, "no cabe discusión alguna respecto de la vinculación de la ley penal con estos principios superiores" (1999, p. 104). Sin embargo, este modelo que venía siendo parámetro ideal y guía de los ordenamientos jurídicos, se enfrentó a un nuevo escenario marcado por la denominada «lucha contra el terrorismo» que ha implicado la priorización del discurso de la seguridad, en palabras del profesor Carvajal

El nuevo orden mundial le ha dado un carácter prioritario a este tipo de lucha, privilegiando discursivamente la seguridad sobre el sistema de garantías jurídicas que

${ }^{1}$ Luigi Ferrajoli desarrolla un sistema garantista para denotar un modelo límite, solo tendencial y nunca perfectamente satisfacible, resultante de 10 principios axiológicos fundamentales, estos son: A1 Nulla poena sine crimine (principio de retributividad o de la sucesividad de la pena respecto del delito); A2 Nullum crimen sine lege (principio de legalidad, en sentido lato o en sentido estricto); A3 Nulla lex (poenalis) sine necessitate (principio de necesidad o de economía del derecho penal); A4 Nulla necessitas sine iniuria (principio de lesividad o de la ofensividad del acto); A5 Nulla iniuria sine actione (principio de materialidad o de la exterioridad de la acción); A6 Nulla actio sine culpa (principio de culpabilidad o de la responsabilidad personal); A7 Nulla culpa sine iudicio (principio de jurisdiccionalidad, también en sentido lato o en sentido estricto); A8 Nullum iudicium sine accusatione (principio acusatorio o de la separación entre juez y acusación); A9 Nulla accusatio sine probatione (principio de carga de la prueba o de verificación); A10 Nulla probatio sine defensione (principio del contradictorio, o de la defensa, o de refutación) (1997, p. 93). 
se construyeron a lo largo de los siglos XVIII, XIX y XX, y que son el fundamento del Estado constitucional. Lo anterior está generando un modelo de Estado que conduce al detrimento de las garantías individuales y a la aparición de una situación de excepción que tiende a la promoción de un Estado de corte autoritario, en contravía del sistema de garantías creado para el cumplimiento de los derechos. (2008, p. 53)

Este nuevo orden mundial, se nos presenta a raíz de un hecho muy concreto: los atentados del 11 de septiembre del 2001, que marcaron en la historia de la humanidad una transformación del orden político y jurídico mundial en cabeza de los Estados Unidos. Así, para hacerle frente al "terrorismo transnacional" se implementaron una serie de medidas de talante militar y policivo, orientadas hacia la seguridad pública y nacional, que en la práctica han resultado en la restricción de derechos fundamentales y en la estructuración de un discurso que construye enemigos y potencia temores y prejuicios en la sociedad.

Es en este sentido que el profesor C. Robin ha analizado el miedo como instrumento de adoctrinamiento interno, que conduce a los individuos a renunciar a ciertas actitudes de resistencia. Indica Robin que

El miedo como represión política es mucho más común en Estados Unidos de lo que nos gustaría creer, se trata de un miedo a las amenazas contra la seguridad física o el bienestar moral de la población frente a las cuales las élites se posicionan como protectoras, o bien el miedo que sienten los poderosos respecto de los menos poderosos, y viceversa. Estos dos tipos de miedo - el primero que une a la nación, y el segundo, que la divide - se refuerzan mutuamente y las élites cosechan el beneficio de sus fuerzas combinadas. El miedo colectivo al peligro distrae del miedo entre élites y clases bajas, o da a estas últimas más razones para temer a las primeras [...] ya sea que el miedo político sea del primero o del segundo tipo, o una combinación de ambos, apoya y perpetúa el dominio de la élite, induciendo a los inferiores a someterse a los superiores sin protestar ni desafiar su poder, sino adaptándose a él. (2009, p. 309)

En este contexto del paradigma securitario, se re-valorizan conceptos de una alta carga subjetivista como «amenaza» o «riesgo» que permiten ampliar la intervención 
del Estado en la vida de los ciudadanos y afinar los controles sociales por parte de las agencias punitivas.

El «riesgo» constituye un elemento del discurso que permea el ámbito de la teoría social y de la criminología. Se parte del supuesto de que existen situaciones de peligro que afectan a todos los miembros de la sociedad y, con base en ello, se sostiene que la mejor manera de prevenir la amenaza consiste en dotar de nuevas técnicas de vigilancia y control a la policía (sistemas de monitoreo) y de herramientas jurídicas como la detención preventiva o administrativa, el incremento de penas y el aumento del número de cárceles. El argumento del riesgo o la amenaza otorga una gran discrecionalidad a la fuerza pública y permite el desarrollo de acciones que vulneran los derechos y las garantías de los individuos. (Carvajal, 2008, p. 62)

En este sentido, la crisis del Estado social y democrático de derecho, se manifiesta, en términos conceptuales, en que el Estado abandona las funciones de legitimación, en aras de funciones de eficiencia, todo lo cual hace necesario un mayor énfasis en el elemento represivo, permitiendo de esta manera que el Estado de policía (autoritario) contenido por el Estado de derecho, salga a flote por su vía de escape predilecta, esto es, a través del derecho penal para apuntalar sus lineamientos autoritarios.

En consecuencia, la crisis del Estado «social de derecho» ha coincidido con una preponderancia del derecho penal como herramienta predilecta del poder hegemónico para "aislar grupos percibidos como peligrosos y neutralizar a sus miembros más perturbadores mediante un seguimiento estandarizado de los comportamientos y una gestión aleatoria de los riesgos" (Wacquant, 1999, p. 99). Este proceso de estigmatización y prejuicio social es aprovechado por los círculos de poder hegemónicos para restringir las libertades públicas y para neutralizar la oposición política o social, desconociendo así sus responsabilidades por la inoperancia y negligencia en la articulación de políticas públicas de carácter social.

Según Carvajal (2008), esta política de seguridad adopta una ideología de talante neoconservador, que ha venido imponiéndose a nivel mundial sobre el paradigma del Estado liberal de derecho, y cuyas principales características son:

En primer lugar, la intensificación del control social por parte del Estado al aumentar las normas represivas y las funciones de vigilancia y control. En segundo lugar, 
profundiza la injerencia de los organismos de seguridad del Estado en la sociedad por medio de medidas preventivas para controlar situaciones de riesgo. En tercer lugar, limita la acción de la administración de justicia [...] afectando la separación de poderes. En cuarto lugar, restringe el Estado de derecho, particularmente con el debilitamiento del sistema garantista [...]. (p. 64)

Así las cosas, la idea de seguridad prevalece sobre conceptos como el de libertad, que fundó el pensamiento del siglo XVIII y XIX, lo que trae como consecuencia el desplazamiento del modelo garantista (descrito anteriormente por los principios sistematizados por Ferrajoli), por el modelo de seguridad.

El actual modelo de seguridad rompe con el paradigma construido por el Estado liberal de derecho, caracterizado por la creación de un sistema jurídico que otorgaba mucha importancia a los principios de libertad, igualdad, legalidad y seguridad jurídica, preceptos protegidos por un amplio sistema de garantías jurídicas. El modelo garantista se quiebra cuando aparecen regímenes que desarrollan sistemas represivos limitando o desconociendo el sistema de garantías mediante la puesta en marcha de mecanismos de excepción, la creación de regulaciones especiales, la implantación de modelos de control social que le restan toda eficacia a los principios garantistas o el desconocimiento del derecho internacional de los derechos humanos. Una última característica del modelo de seguridad vigente es la ampliación de la intervención y el control social por parte de los órganos de seguridad y de policía al amparo de políticas preventivas y de la declaración de situaciones de «riesgo». (Carvajal, 2008, p. 62)

Fruto de esta transformación se configura un Estado "securitario", que ocupa el lugar del Estado "social”, y que tiene como fin esencial proporcionar y garantizar "seguridad" a sus habitantes. Con este objetivo implanta nuevas medidas de control, vigilancia, coacción y represión sobre el conjunto de la población. Para ello apela al uso ya habitual de las instituciones públicas, pero también recurre a empresas y asociaciones privadas, las que, mediante el recurso a las nuevas tecnologías de la información y la comunicación, conforman un nuevo entramado de relaciones en torno a la seguridad (Rivera Beiras et. ál, 2010).

Este contexto securitario pone de manifiesto una de las herramientas predilectas del poder para controlar y someter a sus ciudadanos. Surge aquí el derecho penal 
de emergencia, como mecanismo para hacerle frente a determinadas problemáticas sociales que ponen en jaque la estabilidad del poder. "El derecho penal deja de ser subsidiario, de constituir la ultima ratio de acuerdo con su concepción liberal clásica [...] para devenir en una suerte de panacea con la cual se pretende enfrentar los más diversos problemas sociales" (Baratta, 2004, p. 179).

En efecto, el derecho penal de emergencia es utilizado como dispositivo del poder para hacerle frente a determinadas coyunturas sociales, está dirigido a contener los efectos de las crisis sociales, políticas y económicas que ha vivido el país históricamente. La profusa legislación penal de emergencia se caracteriza por a) fundarse en hechos nuevos o extraordinarios, o bien hacer pasar como hechos nuevos los constantes reclamos sociales; b) la existencia de un reclamo generalizado de la opinión pública, para que la dirigencia "actúe en su pronta solución”; c) la creación de una legislación penal promovida desde los prejuicios y el miedo generalizado con reglas diferentes a las tradicionales del derecho penal liberal (vulnerándose varios de los principios sistematizados por Luigi Ferrajoli citados en precedencia); y, d) la sensación de solución o reducción del reclamo ciudadano, sin atender realmente el problema, convirtiéndose en un derecho penal absolutamente simbólico.

Asimismo, el derecho penal de emergencia se caracteriza por un relajamiento de las garantías penales, -tanto en su estadio de creación legal, como en el momento de su aplicación- de lo cual resulta su inscripción dentro del autoritarismo y la arbitrariedad, en contraposición con el derecho penal propio de un Estado de derecho de características esencialmente liberales y garantistas.

Ahora bien, en lo que respecta a la "técnica legislativa" que inspira la producción de leyes de emergencia en materia penal, resulta evidente el desconocimiento de principios fundamentales que deberían tenerse en cuenta a la hora de promulgar leyes que afectan derechos constitucionales, en efecto, las leyes penales de emergencia $a$ ) adelantan la punición a estados previos a la efectiva puesta en peligro de bienes jurídicos; b) crean de manera artificiosa nuevos bienes jurídicos a proteger; c) utilizan una técnica legislativa que presta mayor énfasis en la casuística, bajo fórmulas legales poco claras, indeterminadas y maleables; y, d) se evidencia un pernicioso retorno a las tesis del derecho penal de autor y no del hecho cometido.

De esta manera, y en plena concordancia con la tesis expuesta por Giorgio Agamben sobre el "Estado de excepción", la suspensión del orden jurídico se convierte en una constante, se vive en tiempos de lo que Agamben ha denominado una "guerra civil legal" (2003, p. 3). De tal manera que el autoritarismo moderno se 
define "a través de la instauración normativa en el marco de un estado de excepción permanente, en el que las personas se reducen a nuda vida, es decir, se les despoja de su condición de ciudadanos y son reducidos a la simple existencia” (2003, p. 27).

En este orden de ideas, el modelo de emergencia penal, pese a mantener mecanismos propios de las nuevas lógicas autoritarias y aparejar consigo elementos que riñen claramente con el Estado de derecho, es lo que más pone en crisis este concepto, toda vez que desconoce sus postulados más básicos, se nos muestra bajo una normalidad aparente contenida dentro de la fórmula puramente nominal y formal del "Estado de derecho".

Precisamente para resistir al estado de policía (autoritario) contenido dentro del Estado de derecho, es que se hace necesario "confrontar el derecho penal vigente con los principios del moderno Estado de Derecho, para el cual el respeto de la dignidad humana es un punto de partida irrenunciable" (Bacigalupo, 1999, p. 244). De tal manera que los principios del «modelo garantista» nos sirvan como indicadores para evidenciar si nos encontramos más próximos a un Estado de derecho real -aquel en el cual estos principios se aplican en mayor medida- o si, por el contrario, estamos más cercanos a un modelo de Estado autoritario que se camufla en la noción, puramente formal, de Estado de derecho y donde estos principios solo cumplen un papel enunciativo sin concreción en la realidad, de tal manera que "la tarea de la ciencia penal consistirá en exigir su plena observancia, con el objetivo de impulsar decididamente su avance” (Ferré Olivé, et ál, 2011, p. 73).

\section{La función esencial del derecho penal del Estado de derecho}

Según Zaffaroni, el derecho penal "no puede hacer otra cosa que proponer la administración optimizada del reducido poder de contención en forma que permita solo el paso del poder punitivo menos irracional, erigiéndose en barrera para el de mayor irracionalidad" (2011a, p. 180, cursiva del original).

La función del derecho penal de todo estado de derecho (de la doctrina penal como programadora de un ejercicio racional del poder jurídico) debe ser la reducción y contención del poder punitivo dentro de los límites menos irracionales posibles. Si el derecho penal no logra que el poder jurídico asuma esta función, lamentablemente habrá 
fracasado y con él habrá caído el estado de derecho. En tal sentido el derecho penal es un apéndice indispensable del derecho constitucional del estado de derecho, que siempre se halla en tensión dialéctica con el estado de policía. El estado de derecho ideal es el instrumento que orienta al derecho penal en todo estado de derecho, marcando los defectos que siempre presenta la realidad y que se establecen por comparación del estado de derecho histórico con el ideal. (2011a, p. 182, cursiva del original) $[\ldots]$

Dada esta función política del derecho penal, éste nunca puede ser neutro, sino que siempre debe ser parcial, en el sentido de que en cualquier circunstancia debe fortalecer la contención de las pulsiones absolutistas, o sea, debe estar siempre del lado del estado de derecho. [...] Referirse a un derecho penal garantista en un estado de derecho es una grosera redundancia, porque en él no puede haber otro derecho penal que el de garantías, de modo que todo penalista, en ese marco, se supone que es partidario de las garantias, esto es, garantista. (2011a, p. 183, cursiva del original)

Bajo este entendido, se ha advertido continuamente que la función del derecho penal consiste en tutelar bienes jurídicos esenciales para la convivencia social de las personas, sin embargo, esta función en palabras de Pavarini es una función ideológica que no tiene relación con la realidad, indica el autor que "asistimos, pues, a la quiebra de la credibilidad de los fines manifiestos del sistema penal, lo que nos empuja, ineludiblemente, a la reflexión sobre sus fines latentes u ocultos, a la reflexión sobre sus funciones materiales y no ideológicas" (1987, pp. 147-148). En similar sentido se expresa Terradillos Basoco cuando señala

[...] en qué medida la criminalización responde a la finalidad de tutelar bienes jurídicos, como continuadamente proclama el poder, o si, por el contrario, busca objetivos distintos, como pueden ser [...] el refuerzo legitimador del poder, o la ocultación de deficiencias en la política social, que se pretenden escamotear mediante la huida al Derecho penal. $(1995$, p. 9)

Resulta ser un lugar común advertir que el sistema penal no funciona. Esta visión está racionalmente basada no solo en las altas cotas que alcanza la reincidencia, sino, y sobre todo, en la gravedad de la cifra negra de la criminalidad, lo que es tanto como constatar que el derecho penal fracasa en sus dos posibles objetivos de 
prevención especial y general. Sin embargo, el fracaso del sistema penal no es tal, ya que no se fracasa si la función realmente importante no es la de prevenir. Tal como argumenta W. Paul:

El hecho de que el control jurídico-penal en la realidad empírica no funcione, radica en que la concepción teórica de un derecho penal orientado hacia fines parte de una ilusión, o sea de presupuestos idealistas, y olvida que [...] según la perspectiva pragmática de la praxis del derecho penal, este no es más que un derecho instrumental, aniquilatorio de enemigos sociales (Feindstrafrechtt); que además la lejana ciencia y filosofía del derecho penal sirven exclusivamente para el uso legitimatorio; que además las cárceles son en realidad funcionalizadas no como instituciones de resocialización, sino como lugares de destrucción psico-física y de internamiento. (1995, p. 69, cursivas y negrilla fuera del original)

Lo anterior ya había sido descrito ampliamente por Foucault cuando advertía sobre la prisión que "lejos de constituir un fracaso, había dado forma a una determinada delincuencia (la de las capas populares), generando una concreta clase de delincuentes y definiendo sus contornos, para disociarlos mejor de otras categorías de infractores que provienen sobre todo de la burguesía" (1984, pp. 39-40). En este sentido, se torna evidente que la función que el derecho penal cumple dentro de determinado modelo de Estado, variará dependiendo de si en este se cumplen los postulados liberales y garantistas propios del Estado de derecho, o por el contrario, se tornara en un instrumento aniquilatorio de enemigos sociales como lo propone W. Paul, situación más cercana al autoritarismo propio del modelo securitario descrito en precedencia.

En este sentido, el derecho penal liberal como derecho penal del Estado de derecho se constituye en modelo ideal, en el deber ser del derecho penal que debe guiar y dirigir las prácticas penales con todas las implicaciones que esto genera -ya advertidas en la sistematización de principios expuesta por Ferrajoli-, y que además se relacionan con el respeto a la autonomía ética, limitación lo más precisa posible del poder público, selección racional de los bienes jurídicos y seguridad jurídica. Así las cosas, a lo que realmente se enfrenta el derecho penal del Estado de derecho es a la arbitrariedad y el autoritarismo en materia penal. El dilema de fondo es derecho penal liberal o derecho penal arbitrario (autoritario). 
Según Zaffaroni (1996) se debe entender por derecho penal del Estado de derecho

[...] aquél que trata de lograr la mayor seguridad en la aplicación del derecho, excluyendo, por ende, en la medida de lo posible, la arbitrariedad en su aplicación. Su opuesto es el Anti-derecho, o sea, toda fuerza tendiente a sembrar la inseguridad, la incertidumbre, el arbitrio personal del poder, la arbitrariedad en el ejercicio del magisterio punitivo. (p. 367, negrilla y cursiva del original)

La arbitrariedad penal es por esencia reactiva, no podría definirse de determinada forma porque es coyuntural, busca defender al poder hegemónico de las reacciones sociales que se generan en determinados momentos y bajo distintas circunstancias, la arbitrariedad no tiene un contenido determinado, puede imponerse echando mano de cualquier tesis autoritaria que tenga al alcance y sirva para conjurar la molestia social. La arbitrariedad penal podrá entonces tener cualquier contenido, valerse de cualquier medio y racionalizarse de cualquier manera. Indica Zaffaroni

La necesaria conclusión de esto es que no existe un concepto o noción autoritaria del derecho penal, sino que se trata de órdenes que emplean cualquier medio teórico, el que más a mano hallan, para eliminar o disminuir la seguridad en la aplicación del derecho y dejar allanado el terreno a la arbitrariedad. (1996, p. 370)

En contraposición, con el derecho penal del Estado de derecho, se nos pone de presente el derecho penal propio del Estado gendarme, este en palabras del profesor argentino Zaffaroni se caracteriza por

[...] no tutelar como bienes jurídicos los elementos de la autorrealización humana, sino que para él -para el Estado gendarme- son bienes jurídicos los que sirven para sostener el estado de cosas por el cual el grupo económicamente poderoso puede someter al resto. [...] Los detentadores de las posiciones de privilegio pasan a defender sus intereses a toda costa. En la defensa de éstos lo inconfesable se torna patente y sus sostenedores se sacuden la molesta estructura del Estado "gendarme" y pasan a adoptar cualquier posición ideológica con que rellenar el derecho penal autoritario y opresivo que crean. La sola descripción de este proceso nos muestra que el derecho penal del Estado "gendarme" resulta opuesto al verdadero derecho 
penal del Estado de derecho, porque, como el Estado "gendarme" desemboca en el autoritarismo, constituye la negación del Estado de derecho. (1996, pp. 371-372)

La circunstancia de que los autoritarismos penales se nos muestren con el ropaje de la "seguridad ciudadana", supuestamente democrática, no puede hacernos caer en confusión, ya se ha advertido suficientemente que el autoritarismo puede echar mano de cualquier mascara ideológica para tratar de ocultar su verdaderas pretensiones que tarde o temprano se revelan.

Es precisamente este derecho penal autoritario que sale a flote en los contextos de miedo e inseguridad, que se empodera bajo las denominaciones de "riesgo", "defensa" y "seguridad" al que debemos denunciar, que debemos desenmascarar porque junto a él se estructura una ideología autoritaria que limita y desconoce los principios fundamentales del Estado de derecho, en suma, de lo que se trata aquí es de una defensa a ultranza del Estado de derecho y del modelo garantista que le es inherente.

\section{Conclusiones}

Es fundamental reivindicar el derecho a la protesta. El respeto por el derecho a protestar y disentir es una garantía democrática propia de un verdadero Estado de derecho, así será la única forma de avanzar en la democratización real.

Creemos que es preciso entender el derecho a la protesta desde un ámbito de libertad, no de prohibición, es decir, la ley como herramienta que permita el desarrollo humano. Desde esta idea, el derecho penal debería ser el último recurso para el tratamiento de un problema social o de un derecho colectivo, as. quienes protestan deban ser tratados como ciudadanos, no como delincuentes, ni mucho menos como enemigos.

De esta manera, cuando el Estado colombiano busca criminalizar la protesta social y contener a los líderes de las movilizaciones haciendo uso del derecho penal de emergencia, es decir cuándo se va rastrillando el Código Penal y se van adicionando delitos que protegen bienes jurídicos superfluos con el fin de encauzar penalmente a quienes no tienen otra salida, otra forma de expresión social que la protesta, los gobiernos no sólo están desconociendo en la práctica el carácter 
democrático y pluralista que exige la Constitución política como forma de ser del Estado colombiano, sino que además está apuntando a objetivos perversos.

\section{Referencias}

Agamben, G. (2003). Estado de excepción. Homo sacer, II, I. Adriana Arango Editora.

Anderson, P. (1979). El Estado Absolutista. España: Siglo XXI Editores.

Bacigalupo, E. (1999). Principios Constitucionales de Derecho Penal. Hammurabi, Buenos Aires-Argentina.

Baratta, A. (2004). Criminología crítica y crítica del derecho penal. Introducción a la sociología jurídico-penal. Argentina: Siglo Veintiuno editores.

Carvajal, J. (2008). La seguridad dentro del Estado de garantías. La seguridad democrática y el caso de las privaciones de la libertad en Colombia durante el periodo 2002-2006. BogotáColombia: Ilsa.

Corey, R. (2009). Elmiedo: historia de una idea política. México: Fondo de Cultura Económica. Fernández, C., Silveira, H.; Rodríguez, G. y Rivera, I. (2010). Contornos bélicos del Estado securitario. Control de la vida y procesos de exclusión social. Barcelona: Anhtropos.

Ferrajoli, L. (1997). Derecho y razón. Teoría del garantismo penal. Madrid: Editorial Trotta. Ferrajoli, L. (2008). Democracia y garantismo. Madrid: Editorial Trotta.

Ferré, J., Núñez, M. y Ramírez, P. (2010). Derecho Penal Colombiano. Parte General. Principios fundamentales y sistema. Grupo editorial Ibáñez.

Gallardo, H. (2005). John Locke y la teoría del poder despótico. Rev. Filosofía Univ. Costa Rica. Recuperado de http://www.vinv.ucr.ac.cr/latindex/filos-105/193_gallardo.pdf

Hobbes, T. (1993). El Ciudadano. Traducción Joaquín Rodríguez Feo. Madrid: Debate.

Hobbes, T. (1994). Leviatán o la materia, forma y poder de una república eclesiástica y civil. Traducción Manuel Sánchez Sarto. México: Fondo de Cultura Económica.

Locke, J. (1994). Segundo tratado sobre el gobierno civil. Traducción Carlos Mellizo. Barcelona: Ediciones Altaya.

Maquiavelo, N. (1978). El Principe. Barcelona: Bruguera.

Melossi, D. (1992). El Estado del Control Social. España: Siglo XXI Editores.

Mir Puig, S. (1994). Función de la pena y teoría del delito en el Estado Social y Democrático de Derecho. Barcelona: Casa Editorial S. A.

Ramírez, J. (2010). Thomas Hobbes y el Estado absoluto: del Estado de razón al Estado de terror. Colombia: Universidad de Antioquía.

Rodríguez, E. (2014). La protesta social en el primer gobierno de Juan Manuel Santos. Colombia: Universidad Nacional. 
Sotelo, I. (2010). El Estado social. Antecedentes, origen, desarrollo y declive. Editorial Trotta. 2010.

Terradillos, J., Hassemer, W., Baratta, A., Melossi, D., Muñoz, J., Edwards, S., Gómez de la Torre, I., Bustos, J., Paul, W. (1995). Pena y Estado. Editorial Jurídica Cono sur. Wacquant, L. (1999). Las cárceles de la miseria. Buenos Aires: Manantial.

Zaffaroni, E. (1996). Tratado de Derecho Penal. Parte General. Argentina: EDIAR.

Zaffaroni, E. (2010). Derecho penal y protesta social. En Bertoni, E. Comp. ¿Es legítima la criminalización de la protesta social? Derecho penal y libertad de expresión en América Latina. Argentina: Universidad de Palermo.

Zaffaroni, E (2011). Estado y seguridad pública: algunas consideraciones básicas. Recuperado de http://www.minseg.gob.ar/estado-y-seguridad-p\%C3\%B Ablica-algu nas-consideraciones-b\%C3\%A1sicas

Zaffaroni, E. (2011a). El enemigo en el derecho penal. Coyoacán. 